\title{
The effects of different levels of calcium supplementation on the bone mineral status of postpartum lactating Chinese women: a 12-month randomised, double-blinded, controlled trial
}

\author{
Zhe-Qing Zhang ${ }^{1,2}$, Yu-Ming Chen ${ }^{2}$, Ruo-Qin Wang $^{2}$, Zhen-Wu Huang ${ }^{3}$, Xiao-Guang Yang ${ }^{3 *}$ and \\ Yi-Xiang $\mathrm{Su}^{2 *}$ \\ ${ }^{1}$ Guangdong Provincial Key Laboratory of Tropical Disease Research, School of Public Health and Tropical Medicine, \\ Southern Medical University, Guangzhou, 510515, People's Republic of China \\ ${ }^{2}$ Guangdong Provincial Key Laboratory of Food, Nutrition, and Health, School of Public Health, Sun Yat-sen University, \\ Guangzhou, Guangdong, 510080, People's Republic of China \\ ${ }^{3}$ Chinese Center for Disease Control and Prevention, Institute of Nutrition and Food Safety, Beijing 100000, People's Republic \\ of China \\ (Submitted 13 May 2015 - Final revision received 1 September 2015 - Accepted 3 September 2015 - First published online 2 November 2015)
}

\section{Abstract}

Increasing dietary $\mathrm{Ca}$ intake may prevent the excessive mobilisation of bone mineral in nursing mothers. We aimed to investigate whether higher $\mathrm{Ca}$ intake could positively modulate the bone mineral changes in Chinese postpartum lactating women. The study was a 12-month randomised, double-blinded, parallel group trial conducted over 12 months. A total of 150 postpartum women were randomly selected to receive either $40 \mathrm{~g}$ of milk powder containing $300 \mathrm{mg}$ of $\mathrm{Ca}$ and $5 \mu \mathrm{g}$ of vitamin D (Low-Ca group) or same milk powder additionally fortified with $300 \mathrm{mg}$ of $\mathrm{Ca}$ (Mid-Ca group) or $600 \mathrm{mg}$ of $\mathrm{Ca}$ (High-Ca group). Bone mineral density (BMD) for the whole body, the lumbar spine, the total left hip and its sub-regions was measured using dual-energy X-ray absorptiometry. A total of 102 subjects completed the whole trial. The duration of total lactating time was 7.9 (SD 2.8) months on average. The intention-to-treat analysis yielded the following mean percentage changes in BMD for the whole body, the lumbar spine and the total left hip, respectively: -0.93 (SD 1.97), 2.11 (sD 4.90 ) and -1.60 (SD 2.65 ) \% for the Low-Ca group; -0.56 (sD 1.89), $2 \cdot 21$ (sD 3.77) and -1.43 (sD 2.30) \% for the Mid-Ca group; and -0.44 (sD 1.67), 2.32 (sD 4.66) and -0.95 (sD $4 \cdot 08$ ) \% for the High-Ca group. The differences between the groups were not statistically significant $(P: 0 \cdot 5-0 \cdot 9)$. The results of the complete case analysis were similar. In sum, we found no significant differences in the bone mineral changes from baseline to 12 months in postpartum lactating women consuming milk powder fortified with different levels of Ca.

Key words: Calcium: Milk: Bone mineral density: Postpartum women: Chinese

Nursing mothers provide their infants with an average of $200-250 \mathrm{mg}$ of $\mathrm{Ca} / \mathrm{d}$, and as much as $400 \mathrm{mg} / \mathrm{d}^{(1,2)}$. The main mechanism by which lactating mothers meet these Ca requirements appears to be a temporary increase in the mobilisation of mineral from the skeleton ${ }^{(3-5)}$. Bone mineral has been reported to decrease by approximately 3-6\% during the first 3-6 months after delivery, especially at sites rich in trabecular bone ${ }^{(6-12)}$.

Theoretically, providing the body with more Ca might be expected to improve bone mineral status during lactation. Maternal dietary $\mathrm{Ca}$ intake has been found to have positive effects on bone health in some observational studies ${ }^{(6)}$ but not in others ${ }^{(13,14)}$. Few randomised placebo-controlled studies lasting for 12 months or less with $1 \mathrm{~g} / \mathrm{d}$ dose in forms of calcium carbonate have been conducted to test this hypothesis on postpartum women with differed habitual $\mathrm{Ca}$ intakes $(283-1300 \mathrm{mg})^{(15-17)}$. In none of these studies, extra Ca has been found to have a beneficial effect on bone mineral during lactation; However, Ca has been shown to have a modest effect after weaning. Nevertheless, the effect of Ca supplementation on bone health during lactation remains unclear, as some researchers have used small study size (fifteen women) ${ }^{(15)}$ or measured few bone sites ${ }^{(17)}$. Additionally, no studies in this area have been conducted on Asian women, whose dietary patterns, lifestyle and hereditary factors may have distinct effects on the regulation of lactation-associated bone changes. Moreover, the supplemental Ca used in previous trials had usually been Calcium carbonate. Ca absorption from animal milks has been shown to be high relative to most other sources, constituting

\footnotetext{
Abbreviations: BMC, bone mineral content; BMD, bone mineral density.
}

* Corresponding author: Y.-X. Su, fax +86 20 87333166, email suyx@mail.sysu.edu.cn; X.-G. Yang, fax +86 10 83132798, email xgyangcdc@vip.sina.com 
approximately $30-35 \%$ of total Ca absorption on average ${ }^{(18)}$. Further investigation is required to determine whether extra $\mathrm{Ca}$ given in the form of milk can facilitate the bone recovery in breast-feeding women.

This randomised, double-blinded, controlled, dose-response trial aimed to examine the effects of different dosages of $\mathrm{Ca}$ administered for 12 months in the form of Ca-fortified milk powder on the bone mineral changes in postpartum breastfeeding Chinese women.

\section{Methods \\ Subjects}

This study included 150 postpartum women aged 20-35 years, living in Guangzhou. The participants were recruited from the Guangdong Women and Children's Hospital and Health Institute between October 2009 and April 2010. All were primiparae who had delivered a normal single infant at full term and intended to breast-feed their child. We excluded the following individuals: those with a history of metabolic bone disease or medical disorders known to affect $\mathrm{Ca}$ and bone metabolism or with a previous fracture history; who used any hormones for $>2$ weeks in the past 1 year; and those with a history of milk allergy or lactose intolerance. Detailed explanations regarding the study purposes, procedure and requirements were given to the subjects. A written informed consent was obtained from all of the participants before the enrolment. The study was approved by the Ethics Committee of Chinese Center for Disease Control and Prevention.

\section{Study design and intervention regimens}

This was a 12-month randomised, double-blinded, controlled trial involving three intervention dosages of $\mathrm{Ca}$. Before being admitted to the study, the subjects received a supplement ( $40 \mathrm{~g}$ of milk powder) for 1 week before delivery as a run-in to familiarise the study's procedure. The subjects who exhibited good compliance and no side effects during the run-in phase were randomly assigned to receive $40 \mathrm{~g}$ of milk powder containing $300 \mathrm{mg}$ of $\mathrm{Ca}$ and $5 \mu \mathrm{g}$ of vitamin D (Low-Ca group) or the same milk powder additionally fortified with $300 \mathrm{mg}$ of $\mathrm{Ca}$ (Mid-Ca group) or $600 \mathrm{mg}$ of $\mathrm{Ca}$ (High-Ca group) for 12 months. Daily doses of 1.0 and $2.0 \mathrm{~g}$ of isolated milk salt (containing 29.2 and $15 \% \mathrm{P}$ ) were added to $40 \mathrm{~g}$ milk powder for the groups of the Mid-Ca and High-Ca group, respectively. All of the supplements shared the same taste, colour, appearance and packaging, which were produced and provided by Nestlé SA. Each daily dose was administered in two packages (approximately $20 \mathrm{~g} /$ package). All of the participants were advised to try to avoid any other milk or dairy products and Ca supplements during the intervention. The clinical trial registration number of this study was ChiCTR-PRC-09000580.

\section{Randomisation and blinding}

An independent researcher used a computer-generated randomisation table with a permuted block size of 15 to assign participants to the three treatment groups receiving different dosages of $\mathrm{Ca}$ in a 1:1:1 ratio. Researchers who had no contact with the study participants and were not involved in data collection and analysis performed the randomisation procedure and the labelling work. The randomised codes were enclosed in sequentially numbered, identical, opaque, sealed envelopes and were drawn by the participants in the order of the final enrolment into the trial. The three supplements were identical in appearance and coded as either A, B or C, respectively, according to strict quality control procedures by the manufacturer. The participants, research assistants and investigators were masked to the treatment group allocation. The code was broken after the completion of data collection by the principal investigator. The proportions of participants who believed that they had received particular treatments did not differ significantly between the three groups, confirming that the blinding was effective (the rates of the correct estimation for the Low-Ca, Mid-Ca and High-Ca were 31, 30 and 35\%, respectively; $P=0 \cdot 9)$.

\section{Compliance and adverse event monitoring}

All of the subjects were instructed to take two packs of milk powder per $\mathrm{d}$ - one in the morning and one in the evening and to keep a daily record of their milk powder consumption. The milk powder was delivered to the participants every 10 weeks, and inquiries were made about leftover packs. Compliance was assessed during the follow-up by calculating the percentage of the delivered packs consumed. Adverse events associated with the supplements were self-reported by the participants during the study.

\section{Data collection}

Anthropometric and bone mineral status measurements. Height was measured to the nearest $0 \cdot 1 \mathrm{~cm}$ and weight to the nearest $0.5 \mathrm{~kg}$ with the subjects in light clothing and without shoes. BMI was calculated as weight $(\mathrm{kg}) /$ height square $\left(\mathrm{m}^{2}\right)$.

The bone mineral density (BMD, $\mathrm{g} / \mathrm{cm}^{2}$ ) and bone mineral content (BMC, g) of the total body, the spine lumbar (L1-4) and the left hip were measured at enrolment (3-7 d after delivery and before discharge from hospital) and after 12 months with dual-energy X-ray absorptiometry (DXA) (Lunar DPX; GE). The subjects wore light clothing with no metal objects during the scan. The final scans of all the skeletal sites were analysed with reference to the baseline scan to minimise errors in positioning the region of interest. To ensure quality control, a spine phantom scan was performed daily. The $\mathrm{CV}$ of the machine between two consecutive BMD measurements taken after repositioning for eleven subjects in same day were 0.68, 1.88, 0.87, 1.29, 1.75 and $2.59 \%$ at the whole body, the lumbar spine, the total left hip, the femur neck, trochanter and Ward's triangle, respectively.

Dietary intake and physical activity assessment. The assessment of dietary nutrient intakes at baseline was based on the FFQ. We asked the participants at 2-3 d after delivery to report the average intake of food per $d$, per week or month 
(depending on the frequency of intake), using the third trimester as a reference period. The participants were asked to complete a 3-d food and physical activity diary before each visit at 3, 6 and 12 months. The diaries were checked further by study investigators at the corresponding visits. Nutrients were calculated from the Chinese Food Composition Tables ${ }^{(19)}$, and the physical activity was calculated by the combination of the metabolic equivalent score (MET, $\mathrm{kJ} / \mathrm{kg}$ per h (kcal/kg per h)) for each type of physical activity after multiplied by its duration per $\mathrm{d}(\mathrm{h} / \mathrm{d})^{(20)}$.

\section{Statistical analysis}

The minimum sample size for assessing the primary outcome measures was calculated using data collected by Kalkwarf et $a l .{ }^{(16)}$, who observed $1.5 \%$ difference in BMD at the lumbar spine between the $\mathrm{Ca}$ and the placebo group after 12-month supplementation at a dosage of $1 \mathrm{~g} / \mathrm{d}$. It was postulated that, with an SD of $2.0 \%$ in the distribution of treatment responses, forty participants per arm could reach over $80 \%$ statistical power to detect a $1.5 \%$ difference in mean percentage change in the lumbar spine BMD between the high- and low-dosage groups (with a significance level of $5 \%$ ). We anticipated a $20 \%$ dropout rate, and therefore fifty subjects were recruited in each group.

Results are expressed as means and standard deviations unless otherwise indicated. The percentage changes in outcome measures were calculated as follows: (follow-up value-baseline value) $100 \%$ /baseline value. The Kolmogorov-Smirnov test was used to check for normality. If the data were not normally distributed, they were transformed before further analysis. The statistical analysis was performed in the following two ways. (1) The changes of BMD/BMC from baseline in all of the subjects ( $n$ 150) were subjected to an intention-to-treat analysis using one-way ANOVA; the dropouts were assigned endpoint values based on a linear regression model. In the regression model, the dependent variable was BMD/BMC at the end of the intervention, and age, group, BMI and baseline BMD/BMC were served as independent variables. The imputed values of the dropouts were calculated using the equation generated from the linear regression model. ANCOVA was used to detect the group differences after adjusting for age, pretreatment values, baseline weight, energy intake and MET. (2) Complete case analysis using ANOVA and ANCOVA was performed on subjects who completed the 12-month intervention ( $n$ 102). Age, pretreatment values, baseline weight and its change, total duration of lactation, physical activity and dietary energy intakes were included as covariates in the ANCOVA analysis. The Bonferroni test was used for post hoc multiple comparisons. The categorical variables were compared using the $\chi^{2}$ test. The data collected from the subjects who completed the whole trial were subjected to step-wise multiple regression analysis to examine the independent effects of group allocation (method $=$ enter) and the other main determinants (methods $=$ step-wise, F-to-enter $=0 \cdot 05$, F-to-remove $=0 \cdot 1$ ). The other independent variables were similar with the covariates in the ANCOVA analysis. Statistical significance was accepted at a two-sided $P$ value of $<0 \cdot 05$. SPSS for Windows, version 17.0 (SPSS Inc.) was applied for the analysis.

\section{Results}

Of the 715 potential subjects that were screened, 150 were eligible and thus randomly assigned to the three treatment groups (Fig. 1). A total of 102 of the subjects completed the full 12-month study. The reasons for discontinuation were pregnancy ( $n$ 8), a change of residence or loss to follow-up ( $n$ 16) and loss of interest ( $n$ 24). The Low-Ca, Mid-Ca and High-Ca groups lost 15,17 and $16(P>0.05)$ subjects, respectively. About $97.5 \%$ of subjects consumed dairy products, and $84.7 \%$ of subjects took $\mathrm{Ca}$ supplements during pregnancy. The three treatment groups were well matched in terms of baseline anthropometrics, nutrients intake and other factors. Mean Ca intakes from foods at the entry of the study were 807,811 and $822 \mathrm{mg} / \mathrm{d}$ in Low-Ca, Mid-Ca and High-Ca groups, respectively $(P=0.9)$ (Table 1$)$. There were no significant differences in baseline characteristics between subjects who completed the study and who did not.

Table 2 summarises the characteristics of the study subjects in the follow-up period. Exclusive breast-feeding lasted for 4.6 (SD 3.3) months. A total of sixty women reported of mixed feeding their babies immediately after delivery. Of the mothers, forty-six lactated for longer than 9 months. Among the nursing mothers, forty-seven resumed their menorrhoea by 6 months after delivery. The subjects' compliance was 76.1, 80.1 and $76.7 \%$ in Low-Ca, Mid-Ca and High-Ca groups $(P>0.5)$, respectively. The mean values for habitual $\mathrm{Ca}$ intakes at 3, 6 and 12 months postpartum were 589 (SD 176), 531 (SD 168) and 591 (sD 187) $\mathrm{mg} / \mathrm{d}$, respectively, and no differences were observed between the three groups $(P: 0 \cdot 226-0 \cdot 785)$. The total $\mathrm{Ca}$ intake during the intervention was calculated as 769, 1067 and $1267 \mathrm{mg} / \mathrm{d}(P<0.001)$ in the Low-Ca, Mid-Ca and High-Ca groups, respectively. No adverse effects were noted, even by the women who consumed $>90 \%$ of the supplements.

The results of the intention-to-treat analysis are shown in Table 3. No group heterogeneities in baseline BMD values were found. After 12-month intervention, the magnitude of the BMD loss at the whole body was highest for Low-Ca group (0.93\%), intermediate for Mid-Ca group (0.56\%) and lowest for High-Ca group (0.44\%). The replenishment of the lumbar spine BMD was also most pronounced in the High-Ca group (3.32\%), followed by the Mid-Ca group (2.21\%) and the Low-Ca group $(2 \cdot 11 \%)$. Similar patterns were observed in the BMD measurements for the total left hip and its sub-regions. After controlling for age, baseline weight, pretreatment values, energy intake and MET, the changes in BMD in the Low-Ca, Mid-Ca and High-Ca groups were, respectively, $-1.00,-0.51$ and $-0.45 \%$ for the whole body, $1.73,1.71$ and $1.94 \%$ for the lumbar spine and $-1 \cdot 60,-1 \cdot 35$, and $-0.99 \%$ for the total left hip. However, those differences were not statistically significant with or without adjustment for covariates $(P: 0 \cdot 2-0 \cdot 9)$. The findings of the complete case analysis indicated that $\mathrm{Ca}$ had no significant effects at either measured site (Table 4). Those results were similar after controlling for covariates (online Supplementary Table S2). In addition, neither intention-to-treat analysis (online Supplementary Table S1) nor complete case analysis (online Supplementary Tables S2 and S3) revealed any statistically significant group differences in BMC at any of the bone sites under study. 


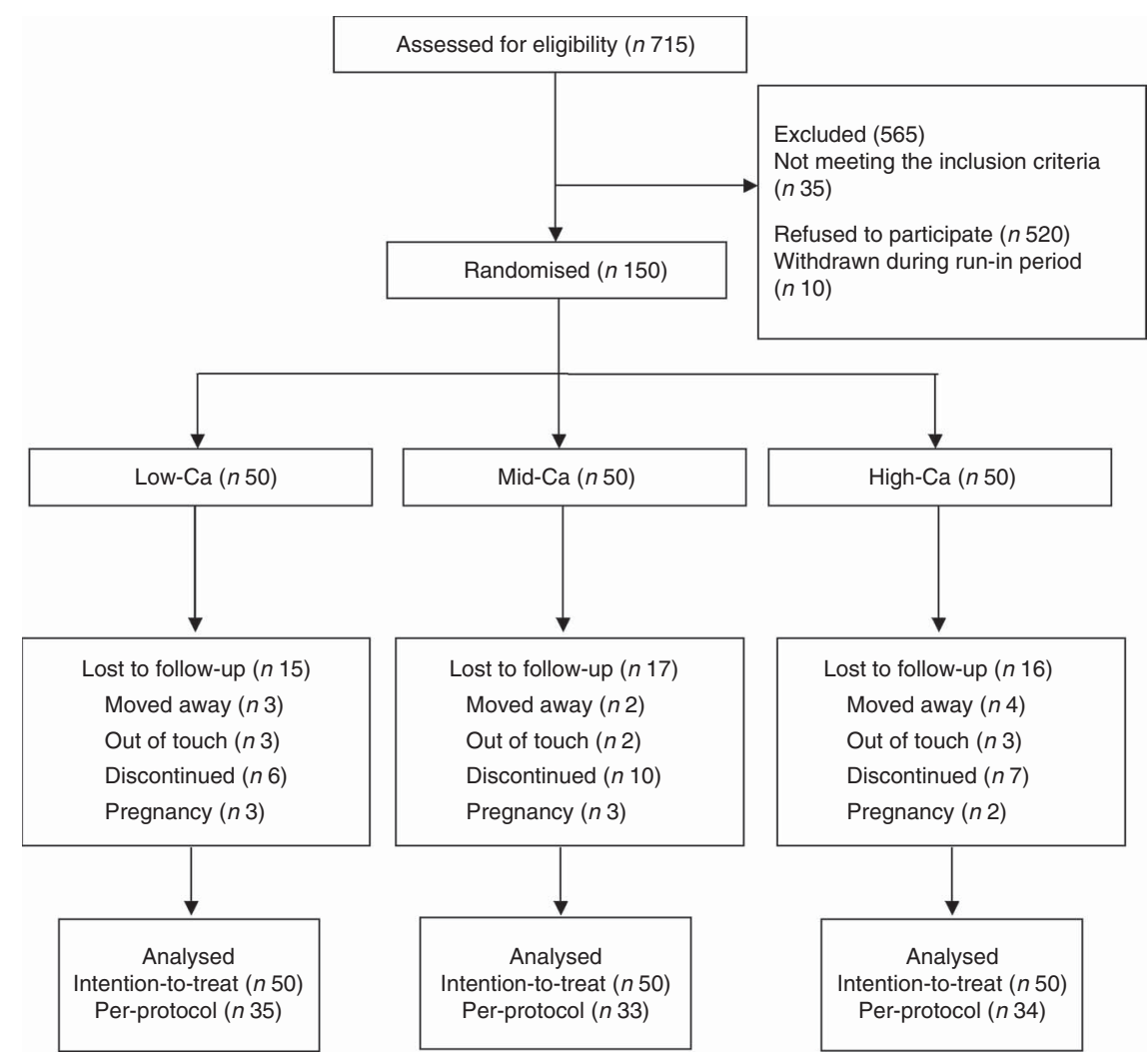

Fig. 1. Box flow of the number of participants recruited and withdrawn from the trial. Low-Ca, low Ca group; Mid-Ca, middle Ca group; High-Ca, high Ca group.

Table 1. Baseline characteristics of the subjects

(Mean values and standard deviations)

\begin{tabular}{|c|c|c|c|c|c|c|c|}
\hline \multirow[b]{2}{*}{ Characteristics } & \multicolumn{2}{|c|}{ Low-Ca $(n 50)$} & \multicolumn{2}{|c|}{ Mid-Ca $(n 50)$} & \multicolumn{2}{|c|}{ High-Ca $(n 50)$} & \multirow[b]{2}{*}{$P$} \\
\hline & Mean & SD & Mean & SD & Mean & SD & \\
\hline Age (years) & $26 \cdot 8$ & $3 \cdot 3$ & $26 \cdot 9$ & $2 \cdot 8$ & $27 \cdot 1$ & 2.5 & 0.9 \\
\hline Height (cm) & $158 \cdot 1$ & 4.6 & $158 \cdot 8$ & $5 \cdot 6$ & $158 \cdot 3$ & $4 \cdot 3$ & 0.8 \\
\hline Weight (kg) & $57 \cdot 6$ & 7.5 & 58.6 & 8 & $60 \cdot 2$ & $9 \cdot 2$ & 0.3 \\
\hline BMI $\left(\mathrm{kg} / \mathrm{m}^{2}\right)$ & $22 \cdot 9$ & $2 \cdot 7$ & $23 \cdot 3$ & $2 \cdot 6$ & $23 \cdot 9$ & $3 \cdot 3$ & 0.2 \\
\hline Gestational weeks & 38.9 & $1 \cdot 1$ & $39 \cdot 2$ & $1 \cdot 1$ & 38.7 & 1.5 & 0.4 \\
\hline Age at menarche (years) & $13 \cdot 4$ & 1.0 & $13 \cdot 8$ & 1.5 & $13 \cdot 2$ & 1.5 & 0.1 \\
\hline Ca supplements use (\%) & \multirow{2}{*}{\multicolumn{2}{|c|}{$\begin{array}{l}88 \\
16\end{array}$}} & \multicolumn{2}{|c|}{84} & \multicolumn{2}{|c|}{82} & 0.7 \\
\hline Multivitamin supplements use (\%) & & & & & & & 0.5 \\
\hline Physical activity (MET-h/d) & 33 & 4.9 & $33 \cdot 7$ & $5 \cdot 1$ & 33.9 & $5 \cdot 7$ & 0.7 \\
\hline \multicolumn{8}{|l|}{ Dietary intakes } \\
\hline Energy intake (kJ/d) & 9954 & 2682 & 9715 & 2151 & 9686 & 2209 & 0.8 \\
\hline Energy intake $(\mathrm{kcal} / \mathrm{d})$ & 2379 & 641 & 2322 & 514 & 2315 & 528 & 0.8 \\
\hline Protein intake $(\mathrm{g} / \mathrm{d})$ & 88.3 & $26 \cdot 5$ & $87 \cdot 7$ & 27.5 & $91 \cdot 6$ & 34.5 & 0.8 \\
\hline Ca intake $(\mathrm{mg} / \mathrm{d})$ & 807 & 318 & 811 & 247 & 822 & 302 & 0.9 \\
\hline$P$ intake $(\mathrm{mg} / \mathrm{d})$ & 1382 & 400 & 1364 & 369 & 1419 & 440 & 0.8 \\
\hline
\end{tabular}

Low-Ca, low Ca group; Mid-Ca, middle Ca group; High-Ca, high Ca group; MET, metabolic equivalent score.

Using multiple linear regression analysis, BMD in the whole body, the lumbar spine, the total hip and the femur neck was found to decrease by $0.20,0.48,0.36$ and $0.38 \%$ (all $P<0 \cdot 01$ ), respectively, with monthly increments in total lactation time. With a 1-kg weight loss, the BMD of the lumbar spine, the total hip, the femur neck and Ward's triangle decreased by $0 \cdot 25,0 \cdot 17,0.26$ and $0.33 \%$, respectively (all $P<0.05$ ) (Table 5).

\section{Discussion}

To the best of our knowledge, we first examined the effects of Ca supplementation on the bone mineral status of Chinese postpartum lactating women. Our findings indicated that postpartum lactating women with a mean total Ca consumption ranging from 762 to $1267 \mathrm{mg} / \mathrm{d}$ in the form of milk powder for 1 year after delivery showed similar bone mineral changes. 
Table 2. Measurements of the study subjects in the follow-up period

(Mean values and standard deviations)

\begin{tabular}{|c|c|c|c|c|c|c|c|}
\hline \multirow[b]{2}{*}{ Characteristics } & \multicolumn{2}{|c|}{ Low-Ca (n 35) } & \multicolumn{2}{|c|}{ Mid-Ca ( $n$ 33) } & \multicolumn{2}{|c|}{ High-Ca ( $n$ 34) } & \multirow[b]{2}{*}{$P$} \\
\hline & Mean & SD & Mean & SD & Mean & SD & \\
\hline Weight (kg) & $50 \cdot 9$ & $7 \cdot 3$ & $50 \cdot 9$ & $9 \cdot 6$ & $54 \cdot 6$ & $9 \cdot 7$ & 0.1 \\
\hline Absolute change of weight over follow-up (kg) & $-6 \cdot 3$ & $5 \cdot 1$ & $-7 \cdot 1$ & $4 \cdot 3$ & $-5 \cdot 1$ & 5.0 & 0.3 \\
\hline Days between baseline and 12 months & 348 & 26 & 341 & 16 & 342 & 18 & 0.3 \\
\hline \multicolumn{8}{|l|}{ Total lactation time (months) } \\
\hline$<6(n)$ & \multicolumn{2}{|c|}{5} & \multicolumn{2}{|c|}{6} & \multicolumn{2}{|c|}{11} & \\
\hline $6-9(n)$ & \multicolumn{2}{|c|}{15} & \multicolumn{2}{|c|}{14} & \multicolumn{2}{|c|}{5} & 0.9 \\
\hline$>9(n)$ & \multicolumn{2}{|c|}{15} & \multicolumn{2}{|c|}{13} & \multicolumn{2}{|c|}{18} & \\
\hline Duration of exclusive breast-feeding (months) ${ }^{*}$ & $4 \cdot 5$ & $2 \cdot 8$ & 4.9 & $3 \cdot 0$ & $4 \cdot 6$ & $3 \cdot 6$ & 0.8 \\
\hline \multicolumn{8}{|c|}{ Time to the resumption of menses (months postpartum) } \\
\hline$<6(n)$ & \multicolumn{2}{|c|}{17} & \multicolumn{2}{|c|}{12} & \multicolumn{2}{|c|}{18} & \\
\hline $6-9(n)$ & \multicolumn{2}{|c|}{8} & \multicolumn{2}{|c|}{14} & \multicolumn{2}{|c|}{9} & 0.6 \\
\hline$>9(n)$ & \multicolumn{2}{|c|}{10} & \multicolumn{2}{|c|}{7} & \multicolumn{2}{|c|}{7} & \\
\hline Compliance (\%) & $76 \cdot 1$ & $17 \cdot 1$ & $80 \cdot 1$ & $12 \cdot 9$ & $76 \cdot 7$ & $17 \cdot 3$ & 0.4 \\
\hline Physical activity (MET-h/d) & $32 \cdot 9$ & $7 \cdot 0$ & $33 \cdot 2$ & $2 \cdot 7$ & $33 \cdot 1$ & 4.4 & 0.9 \\
\hline Energy intake (kJ/d) & 9891 & 1121 & 9791 & 1159 & 9895 & 962 & 0.9 \\
\hline Energy intake $(\mathrm{kcal} / \mathrm{d})$ & 2364 & 268 & 2340 & 277 & 2365 & 230 & 0.9 \\
\hline Protein intake $(\mathrm{g} / \mathrm{d})$ & 96 & 18 & 100 & 15 & 101 & 13 & 0.4 \\
\hline Ca intake $(\mathrm{mg} / \mathrm{d})$ & 769 & 131 & 1067 & 171 & 1267 & 222 & $<0.01$ \\
\hline$P$ intake $(\mathrm{mg} / \mathrm{d})$ & 1402 & 211 & 1556 & 203 & 1698 & 207 & $<0.01$ \\
\hline
\end{tabular}

Low-Ca, low Ca group; Mid-Ca, middle Ca group; High-Ca, high Ca group; MET, metabolic equivalent score.

* Exclusive breast-feeding was defined as baby received nothing but breast milk.

Table 3. The intention-to-treat analysis of means of bone mineral density at baseline and its percentage changes during intervention using ANOVA (Mean values and standard deviations)

\begin{tabular}{|c|c|c|c|c|c|c|c|c|c|c|c|c|c|c|}
\hline & \multicolumn{4}{|c|}{ Low-Ca (n 50) } & \multicolumn{4}{|c|}{ Mid-Ca $(n$ 50) } & \multicolumn{4}{|c|}{ High-Ca ( $n$ 50) } & \multirow[b]{3}{*}{$P^{*}$} & \multirow[b]{3}{*}{$P \dagger$} \\
\hline & \multicolumn{2}{|c|}{ Baseline $\left(\mathrm{g} / \mathrm{cm}^{2}\right)$} & \multicolumn{2}{|c|}{ Change (\%) } & \multicolumn{2}{|c|}{ Baseline $\left(\mathrm{g} / \mathrm{cm}^{2}\right)$} & \multicolumn{2}{|c|}{ Change (\%) } & \multicolumn{2}{|c|}{ Baseline $\left(\mathrm{g} / \mathrm{cm}^{2}\right)$} & \multicolumn{2}{|c|}{ Change (\%) } & & \\
\hline & Mean & SD & Mean & SD & Mean & SD & Mean & SD & Mean & SD & Mean & SD & & \\
\hline Total body & 1.090 & 0.059 & -0.93 & 1.97 & 1.093 & 0.059 & -0.56 & 1.89 & 1.088 & 0.079 & -0.44 & 1.67 & 0.9 & 0.4 \\
\hline Spine & 1.083 & 0.112 & $2 \cdot 11$ & 4.90 & 1.069 & 0.098 & $2 \cdot 21$ & 3.77 & 1.066 & 0.119 & 2.32 & 4.66 & 0.7 & 0.9 \\
\hline \multicolumn{15}{|l|}{ Left hip } \\
\hline Total & 0.942 & 0.084 & -1.60 & $2 \cdot 65$ & 0.944 & 0.098 & -1.43 & $2 \cdot 30$ & 0.923 & 0.123 & -0.95 & 4.08 & 0.5 & 0.6 \\
\hline Femoral neck & 0.922 & 0.079 & -2.31 & 2.59 & 0.915 & 0.110 & -1.56 & 2.52 & 0.897 & 0.115 & -1.09 & 4.46 & 0.5 & 0.2 \\
\hline Trochanter & 0.733 & 0.078 & -1.94 & $4 \cdot 84$ & 0.743 & 0.092 & $-1 \cdot 76$ & 3.07 & 0.712 & 0.116 & -0.86 & $6 \cdot 27$ & 0.3 & 0.3 \\
\hline Ward's triangle & 0.843 & 0.115 & -4.42 & 3.80 & 0.835 & 0.131 & -4.32 & 4.30 & 0.820 & 0.154 & $-3 \cdot 16$ & 5.93 & 0.7 & 0.5 \\
\hline
\end{tabular}

Low-Ca, low Ca group; Mid-Ca, middle Ca group; High-Ca, high Ca group.

* $P$ for the differences of baseline values.

$\dagger P$ for the differences of percentage changes.

Table 4. The complete case analysis of the percentage changes of bone mineral density at measured sites using ANOVA (Mean values and standard deviations)

\begin{tabular}{|c|c|c|c|c|c|c|c|}
\hline & \multicolumn{2}{|c|}{ Low-Ca (n 35) } & \multicolumn{2}{|c|}{ Mid-Ca (n 33) } & \multicolumn{2}{|c|}{ High-Ca (n 34) } & \multirow[b]{2}{*}{$P$} \\
\hline & Mean & SD & Mean & SD & Mean & SD & \\
\hline Total body & -1.00 & $2 \cdot 27$ & -0.51 & $2 \cdot 14$ & -0.45 & 1.80 & 0.5 \\
\hline Spine & 1.73 & 5.53 & 1.71 & 4.15 & 1.94 & 5.23 & 0.9 \\
\hline \multicolumn{8}{|l|}{ Left hip } \\
\hline Total & -1.60 & 2.96 & -1.35 & 2.60 & -0.99 & 4.32 & 0.8 \\
\hline Femoral neck & $-2 \cdot 25$ & 2.93 & -1.41 & 2.90 & -1.08 & 4.95 & 0.4 \\
\hline Trochanter & -1.92 & 5.54 & -1.54 & 3.35 & -1.00 & $6 \cdot 68$ & 0.8 \\
\hline Ward's triangle & $-4 \cdot 21$ & $4 \cdot 31$ & $-4 \cdot 18$ & 5.09 & $-2 \cdot 88$ & $6 \cdot 63$ & 0.5 \\
\hline
\end{tabular}

Low-Ca, low Ca group; Mid-Ca, middle Ca group; High-Ca, high Ca group.

Cross et $a l .{ }^{(15)}$ found that $1 \mathrm{~g}$ of Ca supplement administered daily for 3 months yielded none of the anticipated increase to BMD in women with a habitual Ca intake of $1100 \mathrm{mg} / \mathrm{d}$.
Kalkwarf et $a l .{ }^{(16)}$ reported that $1 \mathrm{~g}$ of elemental $\mathrm{Ca} / \mathrm{d}$ as calcium carbonate given for 6 months showed no effects on bone health in lactating women with a baseline Ca consumption of $614 \mathrm{mg} / \mathrm{d}$. 
Table 5. The final models from multiple regression analysis of the independent effect of group allocation, duration of lactation and other potential predictors on percentage changes of bone mineral density at measured sites*

( $\beta$ Coefficients with their standard errors)

\begin{tabular}{|c|c|c|c|}
\hline & $\beta(\%)$ & SE & $P$ \\
\hline \multicolumn{4}{|l|}{ Total body } \\
\hline Group & 0.338 & 0.248 & 0.2 \\
\hline Total lactation time (months) & -0.197 & 0.074 & 0.01 \\
\hline Constant & 0.192 & 0.774 & 0.8 \\
\hline \multicolumn{4}{|l|}{ Spine } \\
\hline Group & -0.021 & 0.538 & 0.9 \\
\hline Pretreatment value $\left(\mathrm{g} / \mathrm{cm}^{2}\right)$ & $-12 \cdot 382$ & $4 \cdot 127$ & $<0.01$ \\
\hline Total lactation time (months) & -0.480 & 0.161 & $<0.01$ \\
\hline Weight change (kg) & 0.250 & 0.093 & $<0.01$ \\
\hline Constant & $20 \cdot 323$ & 4.524 & $<0.01$ \\
\hline \multicolumn{4}{|l|}{ Total hip } \\
\hline Group & 0.061 & 0.368 & 0.9 \\
\hline Total lactation time (months) & -0.356 & 0.111 & $<0.01$ \\
\hline Baseline weight $(\mathrm{kg})$ & 0.138 & 0.038 & $<0.01$ \\
\hline Weight change $(\mathrm{kg})$ & 0.166 & 0.063 & 0.010 \\
\hline Pretreatment value $\left(\mathrm{g} / \mathrm{cm}^{2}\right)$ & -6.755 & 3.106 & 0.03 \\
\hline Constant & 0.695 & 3.203 & 0.8 \\
\hline \multicolumn{4}{|l|}{ Femoral neck } \\
\hline Group & 0.526 & 0.409 & 0.2 \\
\hline Weight change $(\mathrm{kg})$ & 0.263 & 0.070 & $<0.01$ \\
\hline Total lactation time (months) & -0.377 & 0.121 & $<0.01$ \\
\hline Constant & 1.945 & 1.374 & 0.2 \\
\hline \multicolumn{4}{|l|}{ Trochanter } \\
\hline Group & 0.032 & 0.595 & 0.9 \\
\hline Baseline weight $(\mathrm{kg})$ & 0.199 & 0.061 & $<0.01$ \\
\hline Pretreatment value $\left(\mathrm{g} / \mathrm{cm}^{2}\right)$ & -21.461 & 5.091 & $<0.01$ \\
\hline Constant & 2.458 & 4.602 & 0.6 \\
\hline \multicolumn{4}{|l|}{ Ward's triangle } \\
\hline Group & 0.480 & 0.628 & 0.4 \\
\hline Weight change (kg) & 0.328 & 0.108 & $<0.01$ \\
\hline Constant & -5.076 & 1.402 & 0.1 \\
\hline
\end{tabular}

* Independent variables: the first block variable included group allocation (method enter); age, pretreatment value, the dietary intake of energy, metabolic equivalent score during the follow-up period, weight at baseline and its change and total lactation time were put in the second block (method step-wise). Significance levels for entry and removal from the model were 0.05 and 0.10 . The independent variables are shown in the order they were entered.

In addition, calcium carbonate supplementation $(1 \mathrm{~g} / \mathrm{d})$ for 12 months was found to have no significant effects on the measured bone variables of sixty lactating Gambia women accustomed to a very low Ca intake $(283 \mathrm{mg} / \mathrm{d})^{(4,17)}$. In agreement with those studies, we found that extra Ca supplementation had no beneficial effects on the bone mineral status of Chinese postpartum lactating women.

The effect of Ca supplementation on bone mineral deposition may depend on habitual $\mathrm{Ca}$ intake, and supplementation may primarily affect individuals with low dietary intakes of Ca. Approximately $97.5 \%$ of the women involved in our study consumed milk and dairy products during pregnancy, and $85 \%$ of the participants took Ca supplements. Thus, we cannot rule out the possibility that the null findings of our study are due in part to the participants' high spontaneous Ca consumption at baseline. However, we compared the group differences among those subjects with baseline total Ca intake lower than the median value, and the results were similar (data not shown). In addition, as previously mentioned, a 1-g Ca intervention was found to have no effects on Gambia women with a habitual Ca intake of only $283 \mathrm{mg} / \mathrm{d}^{(17)}$. Additional studies are required to determine the effects of $\mathrm{Ca}$ supplementation on breast-feeding women with a low habitual $\mathrm{Ca}$ intake.

The effects of the supplements on our participants may also have been masked by factors such as lactation duration, weight change, physical activity and intake of other nutrients. However, the three supplements administered in this study had similar nutrient profiles. The participants were asked to maintain their usual dietary habits and patterns of physical activity throughout the study. The three treatment groups exhibited comparable changes in dietary energy and nutrient intake and physical activity levels. Unlike Kalkwarf et $a l^{(16)}$, we did not schedule and individually differentiate lactation period and weaning time, but no statistically significant group differences were observed in breast-feeding time. Therefore, it is very unlikely that these covariates generated bias in our results.

Another alternative possibility for our negative results may be that 12 months was not long enough for some of the changes in bone mineral to take effect. Late lactation and the period immediately post-weaning have been thought to be times of bone recovery ${ }^{(1)}$. Studies have shown that both intestinal $\mathrm{Ca}$ absorption and renal retention of $\mathrm{Ca}$ increase after weaning ${ }^{(21)}$. Additionally, studies on rodents have shown a dramatic increase in bone formation during weaning compared with the lactation period ${ }^{(22,23)}$. These findings suggest that extra $\mathrm{Ca}$ intake may facilitate bone mineral replenishment during weaning. This observation is supported by the pattern of the lumbar spine bone loss recovery in Ca-supplemented and placebo groups observed by Karkwarf et al. ${ }^{(16)}$, who reported a significantly greater increase in bone density in Ca-supplemented group than in placebo group $(5.9$ v. $4.4 \%$; $P<0 \cdot 001)$. In our trial, more than half of the mothers nursed their babies for longer than 9 months, and $3.9 \%$ of women were still breast-feeding at the time of the 12 -month DXA scan. For $55.8 \%$ of the mothers, the final measurements were taken $<3$ months after the cessation of breast-feeding, allowing insufficient time for their bone to respond to the extra Ca. More time may be needed for small incremental benefits to accrue into a measurable outcome. Prolonging the intervention period may augment bone gain of the subjects with higher supplemental Ca. However, an open design of lactating women with a scheduled lactation period of 6 months indicated that daily oral Ca supplements of $1 \mathrm{~g}$ had a transient effect on bone loss, which was negligible at 18 months postpartum ${ }^{(7)}$. More research is necessary to elucidate the influence of the duration of supplementation.

In studies on biomarkers of bone turnover, extra $\mathrm{Ca}$ has been found to have no direct or little effect on the physiological mechanisms that furnish $\mathrm{Ca}$ for breast milk production ${ }^{(4,13,24)}$. It has been proposed that the alteration in $\mathrm{Ca}$ and bone metabolism that accompanies human lactation is a physiological, homoeorhetic response. Many other factors may be involved in directing the Ca flux out of and into the bone ${ }^{(4,25)}$. Parathyroid hormone-related protein derived from the mammary gland has been identified as a prime physiological mediator of bone loss during lactation, in combination with the suppressed oestrogen levels characteristic of lactation ${ }^{(26,27)}$. 
There were several limitations in the present study. First, we experienced a $32 \%$ dropout rate. However, the subjects who completed and those who withdrew from the trial had similar baseline characteristics. Although large samples are generally needed to verify negative findings, we believe that it is unlikely to find a clinically meaningful effect of $\mathrm{Ca}$ on BMD even with a larger sample size, because the BMD changes observed were very small, well within the error of the measurement and would generally not be considered clinically significant. Second, the source of Ca supplement in the present study was milk salt, which also contained other micronutrients except for $\mathrm{Ca}$ (online Supplementary Table S4). However, the content of those nutrients was far below their habitual consumption compared with $\mathrm{Ca}$. Although some of them are also bone-related nutrients, their effects tended to be very small. Third, our study may also have been limited by the absence of a placebo group. We chose not to set up a placebo group, because nearly all the subjects habitually consumed dairy products, and the high consumption of dairy products by Chinese lactating women has also been confirmed by Chen et $a l .{ }^{(28)}$. Therefore, the habitual Ca intake of the participants in the group receiving $300 \mathrm{mg}$ of Ca supplements and avoid other forms of dairy products may well represent that of Chinese lactating women. Fourth, the women were already consuming the supplemented milk powder when the baseline measures were taken. However, the duration was very short (1 week) relative to the length of bone remodelling cycle ( 6 months) ${ }^{(29)}$ and the intervention period (12 months); therefore, this would not affect our estimates. Moreover, we did not assess vitamin D intake because of the absence of data on the vitamin $\mathrm{D}$ content of food in China. We also have not determined the participants' vitamin D status, owing to the limited grants. However, milk powder administered to all of the groups contained the same amount of vitamin $\mathrm{D}(5 \mu \mathrm{g} / \mathrm{d})$, which was below the dietary reference intake for vitamin $D$, established by the Institute of Medicine $(15 \mu \mathrm{g} / \mathrm{d})^{(30)}$. This dosage, which was applied to all women, in addition to the randomised parallel trial design of the study, makes it very unlikely that variation in vitamin D intake biased our results.

In summary, postpartum lactating women with a mean total Ca intake ranging from 762 to $1267 \mathrm{mg} / \mathrm{d}$ exerted similar influences on the bone mineral status through 12-month milk powder intervention.

\section{Acknowledgements}

The authors are grateful to the participants joined in this study and to the doctors and nurses facilitating both the recruitment of participants and the interviews.

The study was supported by the 11th Five Year Key Programs for Science and Technology Development of China (no. 2008BAI58B02).

Y.-X. S. and X.-G. Y. conceived and designed the study and obtained the grants; Z.-Q. Z. and R.-Q. W. collected the data; Z.-Q. Z. and Y.-M. C. analysed the data; Z.-Q. Z. wrote the draft paper; and Z.-W. H. and Y.-X. S. critically revised the paper. All authors approved the final submitted version.

The authors declare no conflicts of interest.

\section{Supplementary material}

For supplementary material/s referred to in this article, please visit http://dx.doi.org/doi:10.1017/S0007114515003967

\section{References}

1. Prentice A (2000) Calcium in pregnancy and lactation. Annu Rev Nutr 20, 249-272.

2. Olausson H, Goldberg GR, Laskey MA, et al. (2012) Calcium economy in human pregnancy and lactation. Nutr Res Rev $\mathbf{2 5}$, 40-67.

3. Ritchie LD, Fung EB, Halloran BP, et al. (1998) A longitudinal study of calcium homeostasis during human pregnancy and lactation and after resumption of menses. Am J Clin Nutr 67, 693-701.

4. Prentice A, Jarjou LM, Stirling DM, et al. (1998) Biochemical markers of calcium and bone metabolism during 18 months of lactation in Gambian women accustomed to a low calcium intake and in those consuming a calcium supplement. $J$ Clin Endocrinol Metab 83, 1059-1066.

5. Sowers M, Eyre D, Hollis BW, et al. (1995) Biochemical markers of bone turnover in lactating and nonlactating postpartum women. J Clin Endocrinol Metab 80, 2210-2216.

6. Krebs NF, Reidinger CJ, Robertson AD, et al. (1997) Bone mineral density changes during lactation: maternal, dietary, and biochemical correlates. Am J Clin Nutr 65, 1738-1746.

7. Polatti F, Capuzzo E, Viazzo F, et al. (1999) Bone mineral changes during and after lactation. Obstet Gynecol 94, $52-56$.

8. Sowers M, Corton G, Shapiro B, et al. (1993) Changes in bone density with lactation. JAMA 269, 3130-3135.

9. Laskey MA \& Prentice A (1999) Bone mineral changes during and after lactation. Obstet Gynecol 94, 608-615.

10. Lopez JM, Gonzalez G, Reyes V, et al. (1996) Bone turnover and density in healthy women during breastfeeding and after weaning. Osteoporos Int 6, 153-159.

11. Kulkarni B, Shatrugna V, Nagalla B, et al. (2009) Maternal weight and lean body mass may influence the lactationrelated bone changes in young undernourished Indian women. Br J Nutr 101, 1527-1533.

12. Chan SM, Nelson EA, Leung SS, et al. (2005) Bone mineral density and calcium metabolism of Hong Kong Chinese postpartum women - a 1-y longitudinal study. Eur J Clin Nutr 59, 868-876.

13. Laskey MA, Prentice A, Hanratty LA, et al. (1998) Bone changes after 3 mo of lactation: influence of calcium intake, breast-milk output, and vitamin D-receptor genotype. Am J Clin Nutr 67, 685-692.

14. Kolthoff N, Eiken P, Kristensen B, et al. (1998) Bone mineral changes during pregnancy and lactation: a longitudinal cohort study. Clin Sci (Lond) 94, 405-412.

15. Cross NA, Hillman LS, Allen SH, et al. (1995) Changes in bone mineral density and markers of bone remodeling during lactation and postweaning in women consuming high amounts of calcium. J Bone Miner Res 10, 1312-1320.

16. Kalkwarf HJ, Specker BL, Bianchi DC, et al. (1997) The effect of calcium supplementation on bone density during lactation and after weaning. $N$ Engl J Med 337, 523-528.

17. Prentice A, Jarjou LM, Cole TJ, et al. (1995) Calcium requirements of lactating Gambian mothers: effects of a calcium supplement on breast-milk calcium concentration, maternal bone mineral content, and urinary calcium excretion. $A m J$ Clin Nutr 62, 58-67.

18. Prentice A (2011) Milk intake, calcium and vitamin D in pregnancy and lactation: effects on maternal, fetal and infant 
bone in low- and high-income countries. Nestle Nutr Workshop Ser Pediatr Program 67, 1-15.

19. Yang Y, Wang G \& Pan X (2002) China Food Composition 2002. Beijing: Peking University Medical Press.

20. Ainsworth BE, Haskell WL, Herrmann SD, et al. (2011) 2011 compendium of physical activities: a second update of codes and MET values. Med Sci Sports Exerc 43, 1575-1581.

21. Kalkwarf HJ, Specker BL, Heubi JE, et al. (1996) Intestinal calcium absorption of women during lactation and after weaning. Am J Clin Nutr 63, 526-531.

22. Ardeshirpour L, Dann P, Adams DJ, et al. (2007) Weaning triggers a decrease in receptor activator of nuclear factorkappaB ligand expression, widespread osteoclast apoptosis, and rapid recovery of bone mass after lactation in mice. Endocrinology 148, 3875-3886.

23. Bowman BM, Siska CC \& Miller SC (2002) Greatly increased cancellous bone formation with rapid improvements in bone structure in the rat maternal skeleton after lactation. $J$ Bone Miner Res 17, 1954-1960.

24. Kalkwarf HJ, Specker BL \& Ho M (1999) Effects of calcium supplementation on calcium homeostasis and bone turnover in lactating women. J Clin Endocrinol Metab 84 464-470.

25. Sowers M, Zhang D, Hollis BW, et al. (1998) Role of calciotrophic hormones in calcium mobilization of lactation. $A m J$ Clin Nutr 67, 284-291.

26. Sowers MF, Hollis BW, Shapiro B, et al. (1996) Elevated parathyroid hormone-related peptide associated with lactation and bone density loss. JAMA 276, 549-554.

27. Dobnig H, Kainer F, Stepan V, et al. (1995) Elevated parathyroid hormone-related peptide levels after human gestation: relationship to changes in bone and mineral metabolism. J Clin Endocrinol Metab 80, 3699-3707.

28. Chen H, Wang P, Han Y, et al. (2012) Evaluation of dietary intake of lactating women in China and its potential impact on the health of mothers and infants.. BMC Womens Health 12, 18.

29. Hadjidakis DJ \& Androulakis II (2006) Bone remodeling. Ann N Y Acad Sci 1092, 385-396.

30. Ross AC, Taylor CL, Yaktine AL, et al. (2011) Dietary Reference Intakes for Calcium and Vitamin D. Washington, DC: National Academies Press. 